Check for updates

Cite this: RSC Adv., 2021, 11, 3808

Received 21st August 2020

Accepted 17th November 2020

DOI: $10.1039 / d 0 r a 07198 f$

rsc.li/rsc-advances

\section{Cellulose nanocrystal assisted trace silver nitrate to synthesize green silver nanocomposites with antibacterial activity $\dagger$}

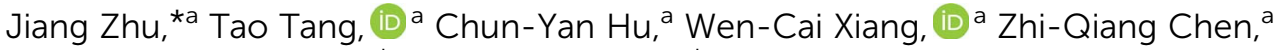
Liu Luo, ${ }^{a}$ He-Shan Yang ${ }^{b}$ and Hong-Pan Liu ${ }^{b}$

Cellulose nanocrystals (CNCs) with silver nanoparticles (AgNPs) are used for applications ranging from chemical catalysis to environmental remediation, and generation of smart electronics and biological medicine such as antibacterial agents. To reduce the synthesis cost of AgNPs and environmental pollution, microwave-assisted generation of AgNPs on the CNC surface (AgNPs@CNC) has been found to be useful, because microwave reaction has the advantages of simple reaction conditions, short reaction time and high reaction efficiency. The silver ions $\left(\mathrm{Ag}^{+}\right)$could be added to the $\mathrm{CNC}$ suspension and placed in the microwave reactor for a few minutes to produce AgNPs. AgNP generation was affected by factors such as the concentrations of $\mathrm{Ag}^{+}$and $\mathrm{CNC}$, and the power of the microwave, as well as the time of reaction. In this study, we used trace amounts of $\mathrm{AgNO}_{3}$ to rapidly synthesize AgNPs using a green microwave-based method instead of Tollen's reagent, and the antibacterial activity of the T1 sample showed that only using $0.03 \mathrm{mM}$ ( 0.01 wt\%) $\mathrm{AgNO}_{3}$ to synthesize AgNPsaCNC could achieve good antibacterial properties.
\end{abstract}

\section{Introduction}

Cellulose nanocrystals (CNCs) are natural and biodegradable rodlike nanoparticles processed from cellulose..$^{1-4}$ As a promising new material, CNCs possess some unique properties, such as large surface area, unique optical character, and high mechanical strength. ${ }^{5}$ Furthermore, CNCs are commercially produced nanomaterials and their surfaces are easily chemically modified, ${ }^{6-8}$ promoting applications in real-life products and services. ${ }^{9}$ At the same time, they possess abundant hydroxyl groups, which assist in their dispersion in water, and charged surfaces. ${ }^{4}$ Owing to these specific physicochemical properties, CNCs can be widely used in scientific research, biological medicine and industrial production, such as drug delivery, bioimaging, tissue engineering, ${ }^{7,10-16}$ catalysis of chemical reactions, ${ }^{17}$ enhancement of functional materials, ${ }^{18-21}$ and the manufacture of luminescent materials. ${ }^{22-25}$ It is remarkable that CNCs can also be used as carriers for many metallic nanoparticles to promote the wide application of metallic nanoparticles. ${ }^{26-31}$

${ }^{a}$ Chongqing Key Laboratory of Environmental Materials \& Remediation Technologies, Chongqing University of Arts and Sciences, Yongchuan 402160, China. E-mail: jiangzhu415@cqwu.edu.cn

${ }^{b}$ College of Chemistry and Environmental Engineering, Chongqing University of Arts and Sciences, Yongchuan 402160, China

$\dagger$ Electronic supplementary information (ESI) available. See DOI: 10.1039/d0ra07198f
Antibacterial agents play an important role in eradicating bacteria and protecting human health. ${ }^{32}$ In particular, pathogenic Escherichia coli (E. coli) and Staphylococcus aureus (S. aureus) can cause health-threatening diseases such as clinical mastitis, ${ }^{33}$ dysentery $^{34}$ and diarrhoea. ${ }^{35}$ Developing a stable, efficient and low-cost antibacterial agent is an urgent problem to be solved. AgNPs are the most common commercial antimicrobial nanomaterials. ${ }^{36-38}$ Although the antibacterial mechanism of AgNPs are not fully understood, several articles have reported that AgNPs adsorbed on the cell membrane to change its permeability and disturb its normal physiological functions. ${ }^{39-41}$ AgNPs are among the most valuable nanoparticles with superior properties, such as high antibacterial activity, which renders them suitable for using in tissue scaffolds, wound dressings, and protective clothing. ${ }^{26}$ In the past, AgNPs were synthesized by carrying on the surface of many materials, such as chitosan, ${ }^{42-44}$ kappa-carrageenan ${ }^{45}$ cyclodextrin ${ }^{31}$ and graphene. ${ }^{46,47}$ As for the reduction of AgNPs on the surface of these materials, it is insufficient to widen the application of AgNPs that the materials cannot reach the nanometer scale, that the reduction process is expensive, that their dispersion in water is poor. However, CNC can facilitate the nucleation of metal nanoparticles from metallic salts with the assistance of reducing agents, while preventing the aggregation of metallic nanoparticles, to reach a narrow size distribution. For instance, $\mathrm{Ag}^{+}$can be reduced to AgNPs using sodium borohydride $\left(\mathrm{NaBH}_{4}\right)$ on the surface of CNC. ${ }^{18,48-51}$ In addition, glucose was applied as the reducing agent and CNC as the substrate to synthesize AgNPs from 
Tollen's reagent $\left(\mathrm{Ag}\left(\mathrm{NH}_{3}\right)_{2} \mathrm{OH}\right) .{ }^{9}$ Although the synthesis of antimicrobial AgNPs using these methods has been successful, it still poses certain restrictions on the end product. The raw materials used in these methods are toxic or expensive, and they cannot be applied for the development of green and economic methods for synthesis of AgNPs.

Recently, microwave reaction instruments were widely used to assist in the synthesis of AgNPs, and the synthesized AgNPs had a high antibacterial activity. ${ }^{52-55}$ Therefore, most studies have considered how to ameliorate the antibacterial activity of AgNPs as well as abate the addition amount of AgNPs. In this study, we used glucose as the reducing agent and CNC as the carrier to synthesize AgNPs in a microwave. The AgNPs prepared under different reaction conditions were characterized using UV/visible spectrometry. The AgNPs generated on the surface of CNC using the microwave reaction can be utilized to produce green and inexpensive AgNPs. This method of synthesizing AgNPs is simple and only requires trace amounts of silver nitrate, which can be further developed for large-scale commercial production of AgNPs.

\section{Experimental}

\subsection{Materials}

Cellulose microcrystalline (CMC) and silver nitrate $\left(\mathrm{AgNO}_{3}, \mathrm{AR}\right)$ were manufactured by Sinopharm Chemical Reagent Co., Ltd. (Shanghai, China). D-Glucose monohydrate $\left(\mathrm{C}_{6} \mathrm{H}_{12} \mathrm{O}_{6} \cdot \mathrm{H}_{2} \mathrm{O}, \mathrm{AR}\right)$ and sodium hydroxide ( $\mathrm{NaOH}, \mathrm{AR})$ were produced by Chengdu Kelong Chemical Reagent Factory (Chengdu, China). All the reagents were used without further purification.

\subsection{Preparation of $\mathbf{C N C}$}

$\mathrm{H}_{2} \mathrm{SO}_{4}$ solution was used to hydrolyze CMC during the preparation of CNC. ${ }^{56}$ First, $12.5 \mathrm{~g}$ of CMC was added to $64 \mathrm{wt} \% \mathrm{H}_{2} \mathrm{SO}_{4}$ $(200 \mathrm{~mL})$ and the mixture was stirred at $50{ }^{\circ} \mathrm{C}$ for $4 \mathrm{~h}$. Fivefold volume deionized water was then applied to the mixture to stop the reaction. The suspension was centrifuged to obtain crystals, which were washed in deionized water, centrifuged and separated again. This step was repeated five times for sample. Dialyzed against deionized water for several days until the water $\mathrm{pH}$ reached a value of 6.0-7.0. Finally, sample was freeze-dried for $24 \mathrm{~h}$ and stored in vacuum until use. In this experiment, the morphology of the CNC was characterized by a TEM with carbon-coated copper support grids (Fig. S1 $\dagger$ ), and the length of $\mathrm{CNC}$ was maintained at approximately $100 \mathrm{~nm}$ to $300 \mathrm{~nm}$.

\subsection{Optimization of AgNPs generation by orthogonal assay design}

An orthogonal assay (Table 1) was designed to research the effects of CNC, silver ions, ultrasonic power, and reaction time on preparation of AgNPs. This orthogonal assay was used to find the optimized condition for production of AgNPs. In this experiment, $\mathrm{AgNO}_{3}, \mathrm{NaOH}$ and glucose (molar ratio $1: 1: 2$ ) were used raw materials to synthesize AgNPs in $50 \mathrm{~mL}$ CNC dispersion.

The reduction reaction was carried out by in a microwave oven (MCR-3, Gongyi yuhua instrument Co., Ltd, China) at different power and time. After reaction, the products were dialyzed against Milli-Q water in dark for 4 days at room temperature.

\subsection{Characterization}

UV-vis absorption spectra of AgNPs@CNC was taken over the wavelength range 200 to $800 \mathrm{~nm}$ using UV-vis spectrophotometer model UV-5500 (Shanghai METASH, China).

Morphology of AgNPs@CNC was observed on a GeminiSEM 300 (ZEISS, Germany) scanning electron microscope (SEM), and AgNPs@CNC was analyzed by energy dispersive spectrometer (EDS).

X-ray diffraction (XRD) patterns of AgNPs@CNC samples were measured by a DX-1000 diffractometer (Dandong Tongda Instrument Co., Ltd, China) using a CuK $\alpha$ radiation. The voltage and current were set to $30 \mathrm{kV}$ and $20 \mathrm{~mA}$, respectively. Diffraction patterns were recorded for $2 \theta$ values ranging from $5^{\circ}$ to $80^{\circ}$ at a scanning rate of $0.04^{\circ} \mathrm{s}^{-1}$.

FTIR spectra of the dried CNC and AgNPs@CNC samples were reported on a L1600400 Spectrum TWO DTGS spectrometer (Made in Liantrisant, UK) in the region of $4000-400 \mathrm{~cm}^{-1}$.

The X-ray photoelectron spectra of AgNPs@CNC were reported with an X-ray photoelectron spectrometer (XPS, Thermo Scientific). XPS was used by methods of a flood gun charge neutralizer system equipped with an Al Ka X-ray source $(h \nu=1486.6 \mathrm{eV})$.

The zeta potentials of AgNPs@CNC were measured using a dynamic light scattering (DLS) by 90plus PALS model (Brookhaven, USA). All measurements were implemented in triplicate.

Thermogravimetric analyses (TGA) were performed using NETZSCH STA449F3 thermogravimetric analyzer (Netzsch-

Table $1 \quad L 9\left(3^{4}\right)$ Design of Orthogonal Array

\begin{tabular}{|c|c|c|c|c|c|}
\hline$\#$ & $\mathrm{CNC}\left(\mathrm{mg} \mathrm{mL}{ }^{-1}\right)$ & $\mathrm{Ag}^{+} \times 10^{-2}(\mathrm{mM})$ & Power $(\mathrm{W})$ & Time (s) & UV/vis absorbance at $410 \mathrm{~nm}$ \\
\hline $\mathrm{T} 1$ & 1.5 & 3.00 & 320 & 200 & 0.80 \\
\hline $\mathrm{T} 2$ & 1.5 & 1.50 & 240 & 250 & 0.39 \\
\hline $\mathrm{T} 4$ & 0.5 & 3.00 & 240 & 300 & 0.56 \\
\hline T5 & 0.5 & 1.50 & 160 & 200 & 0.29 \\
\hline T6 & 0.5 & 0.75 & 320 & 250 & 0.24 \\
\hline T9 & 0 & 0.75 & 240 & 200 & 0.10 \\
\hline
\end{tabular}


Gerätebau $\mathrm{GmbH}$, Selb, Germany). Materials were heated from 25 to $600{ }^{\circ} \mathrm{C}$ using a heating rate of $10{ }^{\circ} \mathrm{C} \min ^{-1}$ under a nitrogen flow (50 $\left.\mathrm{mL} \mathrm{min}^{-1}\right)$.

\subsection{Antibacterial tests}

The antibacterial activity of the orthogonal array samples (T1-T9) were tested inhibition Gram-negative bacteria E. coli and Grampositive bacteria $S$. aureus using the agar-diffusion approach. Bacteria were grown in the Luria-Bertani (LB) liquid medium (5 $\mathrm{g}$ $\mathrm{L}^{-1}$ casein tryptone, $2.5 \mathrm{~g} \mathrm{~L}^{-1}$ yeast extract, $5 \mathrm{~g} \mathrm{~L}^{-1} \mathrm{NaCl}$, and $500 \mathrm{~mL}$ deionized water, $\mathrm{pH} 7)$ at $37^{\circ} \mathrm{C}$ for $24 \mathrm{~h}$ on a shaker bed at

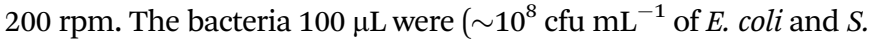
aureus) coated on the Luria-Bertani (LB) agar plates, and then 150 $\mu \mathrm{L}$ of orthogonal array samples were deposited and in wells (diameter $=7 \mathrm{~mm}$ ) formed in the agar plates, and those plates were cultured at $37{ }^{\circ} \mathrm{C}$ for $24 \mathrm{~h}$. Then, the ranges of the inhibition zone (i.e., transparent area) were measured using a vernier caliper. All AgNPs@CNC samples were measured in triplicates.

Using the standard dilution method which determined the minimum inhibitory concentration (MIC) of $\mathrm{T} 1$ sample, MIC is defined as the minimum $\left[\mathrm{Ag}^{+}\right]$at which no bacterial turbid is viewed in all three parallel experiments after coculturing bacteria with AgNPs/CNC for $24 \mathrm{~h}$, in this research. The $\mathrm{T} 1$ sample of $\mathrm{Ag}^{+}$ concentration was examined with inductively coupled plasma optical emission spectroscopy (ICP-OES, Perkin-Elmer, Optima 5300DV, USA). $E$. coli and $S$. aureus were cultured in the Luria-Bertani (LB) medium $\left(10 \mathrm{~g} \mathrm{~L}^{-1}\right.$ casein tryptone, $5 \mathrm{~g} \mathrm{~L}^{-1}$ yeast extract, and $10 \mathrm{~g} \mathrm{~L}^{-1}$ $\mathrm{NaCl}, \mathrm{pH} 7$ ) at $37{ }^{\circ} \mathrm{C}$ on a shaker bed at $200 \mathrm{rpm}$. $\mathrm{Ag}^{+}$of different concentrations was prepared in each germfree test tube and inoculated with $4.8 \times 10^{6} \mathrm{CFU} \mathrm{mL}^{-1}$ bacteria suspension for $24 \mathrm{~h}$.

\section{Results and discussion}

\subsection{Microwave-assisted generation of AgNPs}

Microwave reaction instruments could provide high energy in a very short time. $\mathrm{Ag}^{+}$was added to the CNC suspension and placed in the microwave reactor for a few minutes to produce AgNPs. Images of the AgNPs@CNC suspensions prepared according to the orthogonal assay (T1-T9) described above are presented (Fig. 1a). The formation of light yellow AgNPs@CNC of nanoparticles was obvious from visual inspection of the reagents following microwave reaction. ${ }^{57}$ The color of AgNPs varies with the conditions of the orthogonal assay. The synthesis of AgNPs was confirmed by UV-vis spectrophotometry. UV absorption spectral intensity was chosen as an indicator for the selection of optimal conditions. Fig. 1b showed an absorbance spectrum with a peak at approximately $420 \mathrm{~nm}$, indicating the formation of AgNPs, because the color and absorption spectra of samples at $420 \mathrm{~nm}$ is attributed to the excitation of surface plasmon vibrations of $\mathrm{Ag}$ atoms. ${ }^{58,59}$

We selected the optimal orthogonal assay conditions for synthetic AgNPs based on the intensity of UV-vis absorbance. The extreme range analysis of the intensity of UV absorption peak at $420 \mathrm{~nm}$ (Table S1 $\dagger$ ) indicated that the optimal AgNPs synthesis conditions were T1. Therefore, T1 sample was selected as the main characterization sample. All samples were freeze dried for $24 \mathrm{~h}$ and stored in vacuum before use. The samples (T7-T9) did not perform the next characterization because the absorbance of these samples was weak and the amount of sample after drying was very small.

\subsection{Morphology of AgNPs@CNC}

The surfaces of CNC had largely dense little light spots in the SEM of the T1 sample (Fig. 2). Similarly, the SEM image of the samples (T2-T4) obviously showed the presence of little spots on the surface, but the small spots of the samples is rarely relative to T1 sample. Meanwhile, it was not obvious that little light spots were observed in the samples (T5-T6). And the T5-T6 samples could only see the agglomerated CNC after drying. In the above analysis, it could be roughly considered that the small light spots were AgPNs, because the number of spots in the image of the SEM and the intensity of the UV-vis absorbance peak were mutually confirmed. In addition, the diameter of AgNPs was very small on the surface of CNC. This showed that AgNPs was not easily observed at the submicron scale. Fig. 2 shown the EDS spectrum for the T1 sample. The peaks of silver in the EDS images confirmed that the adsorption of AgNPs took place on the surface of CNC. In addition to the characteristic peaks of AgNPs, other peaks for primary elements, i.e., $\mathrm{C}, \mathrm{O}, \mathrm{Na}$, and $\mathrm{S}$, were also exhibited. The display of these additional peaks in the EDS spectra were mainly due to the composition of the CNC and media containing these essential elements.

\subsection{X-ray diffraction (XRD) analysis}

The XRD was used to explain and characterize the structure of the AgNPs generation (Fig. 3). Because the crystallization peak

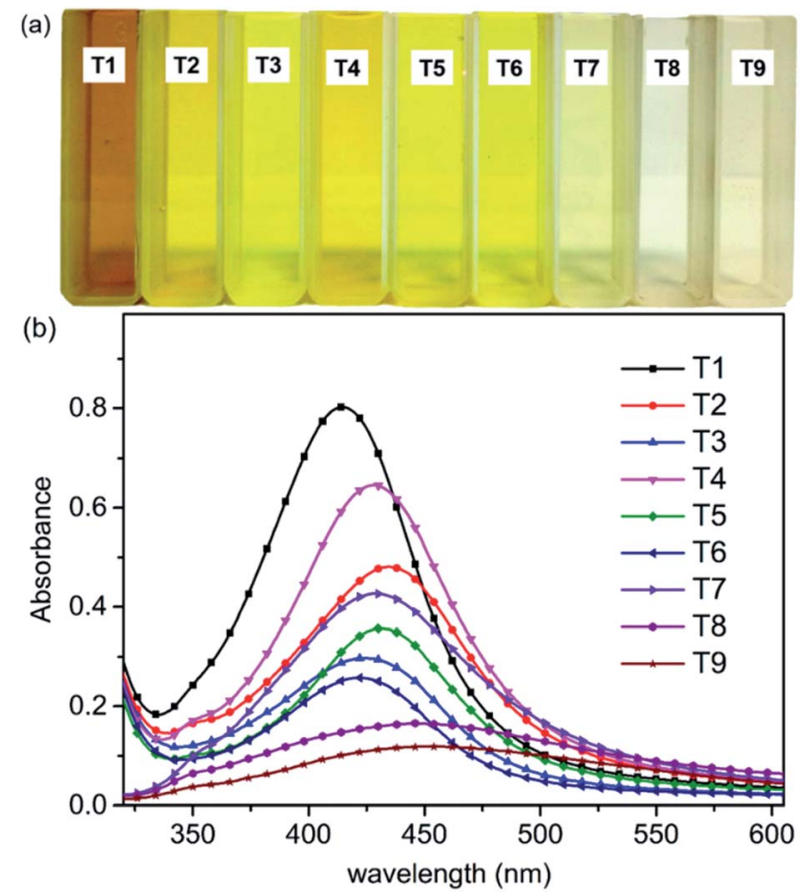

Fig. 1 (a) Nanoparticle suspensions and (b) UV spectra of AgNPs@CNC (T1-T9). 

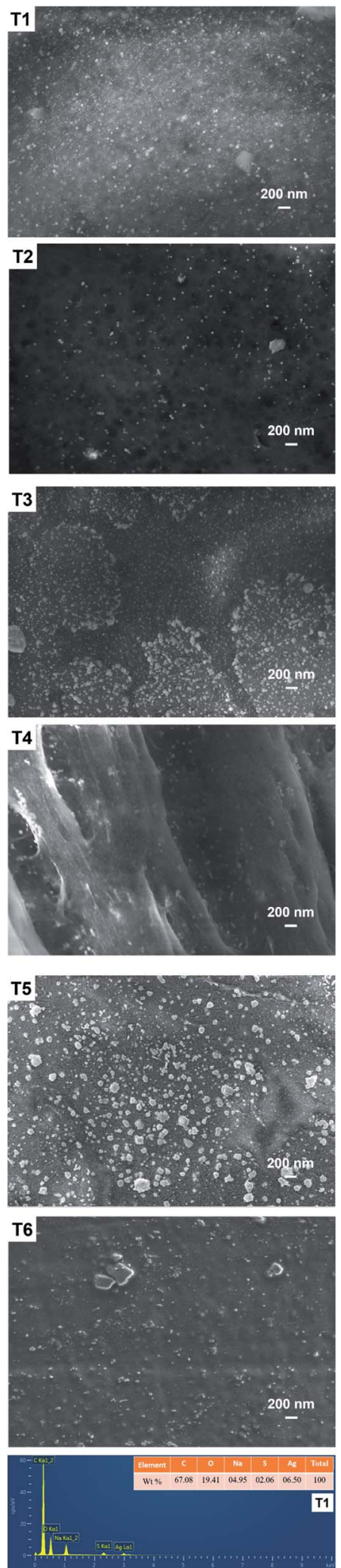

Fig. 2 FE-SEM images of AgNPs@CNC (T1-T6) and the EDS curve for T1.

intensity of pure $\mathrm{CNC}$ (Fig. $\mathrm{S} 2 \dagger$ ) is too high, it was difficult to view the crystallization peak of Ag on the figure of the XRD curve of pure CNC and the curve of the orthogonal array samples.

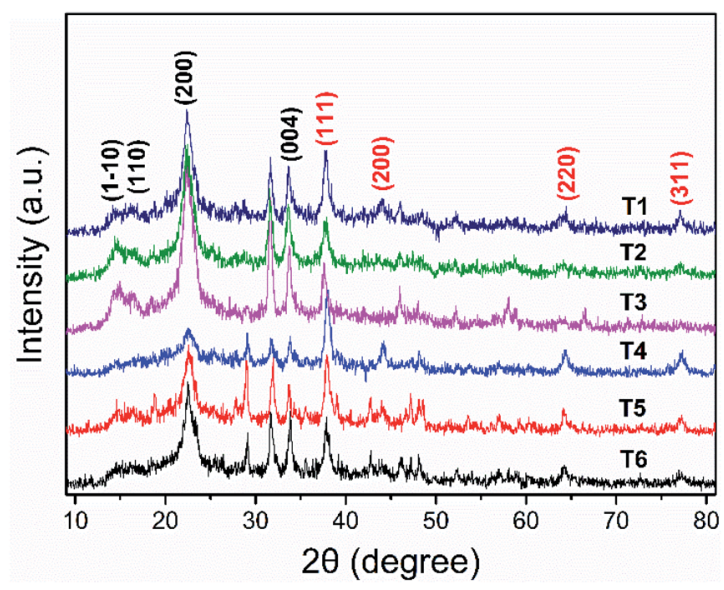

Fig. 3 Wide-angle XRD patterns of the samples (T1-T6).

Therefore, we only gave the representative XRD patterns of AgNPs@CNC prepared from orthogonal assay samples (T1-T6). All samples revealed four typical diffraction peaks at about $2 \theta=$ $14.5^{\circ}, 2 \theta=16.5^{\circ}, 2 \theta=22.6^{\circ}$ and $2 \theta=34.0^{\circ}$, which were attributed to the presence of $\mathrm{CNC}$, corresponding to (1-10), (110), (200) and (004) planes, respectively. ${ }^{60,61}$ Additional other small peaks from $30^{\circ}$ to $80^{\circ}$ in curves (T1-T6) were assigned to diffractions from AgNPs. The diffraction peaks from the AgNPs@CNC at about $38.1^{\circ}, 44.4^{\circ}, 64.4^{\circ}$ and $77.5^{\circ}$, consistent with the crystalline planes of (111), (200), (220) and (311), respectively. ${ }^{62}$ There was a face-centered cubic (fcc) structure confirmed of crystalline AgNPs, according to the existence of these crystallization peaks. ${ }^{63}$ XRD pattern analysis was used to further illustrate the AgNPs on the surface of CNC under the trace silver ion concentration, because the XRD pattern exhibited extremely small characteristic peaks of AgNPs.

\subsection{Chemical structure characterization of AgNPs@CNC}

The FTIR spectra of pure CNC and AgNPs@CNC were almost the same with each other (Fig. 4a). The main peak was $\mathrm{OH}$ stretching band at $3000-3700 \mathrm{~cm}^{-1}$ and $\mathrm{CH}$ stretching band at $2800-3000 \mathrm{~cm}^{-1}$. The peak located at $1633 \mathrm{~cm}^{-1}$ could be attributed to the absorbed moisture in the CNC. There were many weak strength peaks at $1250-1500 \mathrm{~cm}^{-1}$ and the explanation of these peaks need further studies. In conclusion, AgNPs@CNC did not form a new peak or the disappearance of the old peak compared with the pure CNC. This might be because the AgNPs were merely physically adsorbed and did not form chemical bonds on the CNC surface.

To further identify the synthesized AgNPs, element analyses of the sample were carried out by XPS. XPS survey of the pure CNC exhibited the peaks for C 1s $(\sim 286 \mathrm{eV}), \mathrm{O} 1 \mathrm{~s}(\sim 532 \mathrm{eV})$ and $\mathrm{S} 1 \mathrm{~s}(\sim 169 \mathrm{eV})$. In addition, XPS survey of the AgNPs@CNC revealed the peaks for $\mathrm{Na} 1 \mathrm{~s}(\sim 1072 \mathrm{eV}), \mathrm{C} 1 \mathrm{~s}(\sim 286 \mathrm{eV}), \mathrm{O} 1 \mathrm{~s}$ $(\sim 532 \mathrm{eV})$ and S 1s $(\sim 169 \mathrm{eV})$, and then AgNPs deposition on the $\mathrm{CNC}$ was confirmed by the appearance of $\mathrm{Ag} 3 \mathrm{~d}$ doublet near $370 \mathrm{eV}$ as shown in Fig. 4b. The high resolution Ag $3 \mathrm{~d}$ spectrum exhibited in Fig. 4c was composed of two different peaks with 

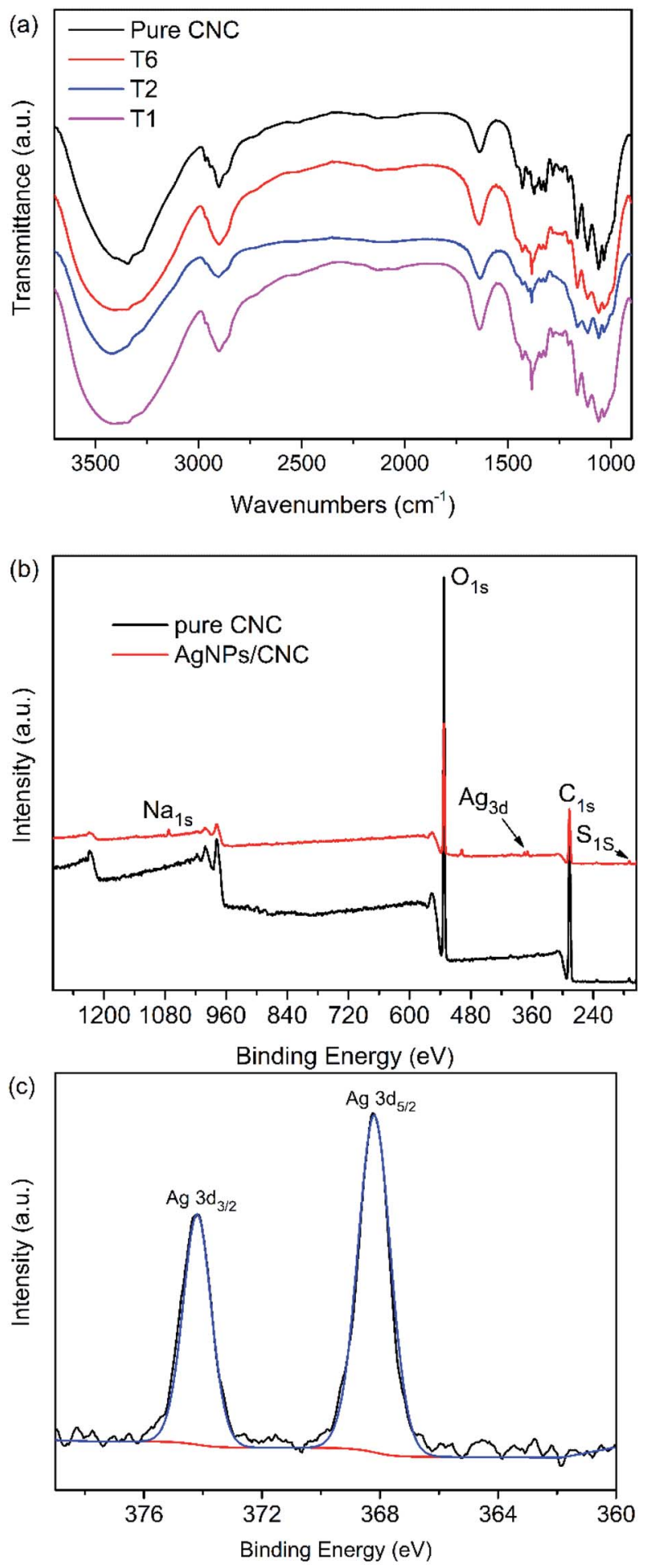

Fig. 4 (a) FT-IR spectra of the pure CNC, T1, T2 and T6. (b) XPS spectra of the pure CNC and T1. (c) High resolution Ag 3d spectrum of the AgNPs@CNC.

binding energies of $\mathrm{Ag} 3 \mathrm{~d}_{3 / 2}$ and $\mathrm{Ag} 3 \mathrm{~d}_{5 / 2}$ at 368.2 and $374.2 \mathrm{eV}$, respectively, both ascribed to the $\mathrm{Ag}^{0}{ }^{0}{ }^{29}$ These peaks located at lower binding energies should not be appointed to oxidised silver compounds, because $\mathrm{Ag} 3 \mathrm{~d}$ in oxides were located at more powerful binding energies, e.g. $\mathrm{Ag} 3 \mathrm{~d}_{5 / 2}=367.7 \mathrm{eV}$ for $\mathrm{Ag}_{2} \mathrm{O}$ and
$367.4 \mathrm{eV}$ for $\mathrm{AgO} .{ }^{64}$ These peaks also cannot be ascribed to the structure of $\mathrm{Ag}^{-} \mathrm{C}_{5 / 2}(\sim 366 \mathrm{eV})$ and $\mathrm{Ag}-\mathrm{C}_{3 / 2}(\sim 372 \mathrm{eV})$ components. ${ }^{65,66}$ Moreover, the $6 \mathrm{eV}$ dividing of the $3 \mathrm{~d}$ doublet due to the spin-orbit coupling authorized the presence of $\mathrm{Ag}^{0}$ state on the CNC surface. ${ }^{67,68}$

\subsection{Zeta potential analysis of the stability of AgNPs@CNC suspension}

The zeta potential was a considerable parameter for determining the stability of AgNPs@CNC suspensions. For a physically stable nanoparticle suspension to be stabilized solely by electrostatic repulsion, a zeta potential of $\pm 30 \mathrm{mV}$ was required as a minimum. ${ }^{69}$ Zeta potential data of the AgNPs@CNC were exhibited in Fig. 5. These showed that the AgNPs@CNC had a high stability of the suspension, because samples potential values were $>30 \mathrm{mV}$ except the $\mathrm{T} 2$. Although the zeta potential value of the T1 sample was not the highest among all samples, it was about $33.16 \pm 3.06 \mathrm{mV}$ that was $10.5 \%$ higher than $30 \mathrm{mV}$. In addition, the zeta potential value of the $\mathrm{T} 1$ sample was higher than the value $31.13 \pm 2.54 \mathrm{mV}$ of pure $\mathrm{CNC}$ suspension. This indicated that controlling the appropriate amount of reduction of AgNPs on the surface of CNC did not affect the dispersion of CNC in deionized water, and $\mathrm{T} 1$ samples could be as stable as pure CNC suspensions.

\subsection{Thermal stability analysis of AgNPs@CNC}

Fig. 6a shown the TGA curves of pure CNC and the sample of T1. But the first mass loss of the materials was the same, two samples revealed different thermal degradation processes. The first mass loss in the range $50-100{ }^{\circ} \mathrm{C}$ was ascribed to the vaporization of water loosely bound to the materials. The next degradation procedure in the range of $130{ }^{\circ} \mathrm{C}$ to $400{ }^{\circ} \mathrm{C}$ was related to the dehydration and depolymerisation processes, followed by the generation of char residue at temperatures above $400{ }^{\circ} \mathrm{C}$. The intermediate thermal degeneration of the CNC was generally associated with the formation of crosslinked structures from the radical products, which leads to the generation of thermally steady materials that were included in

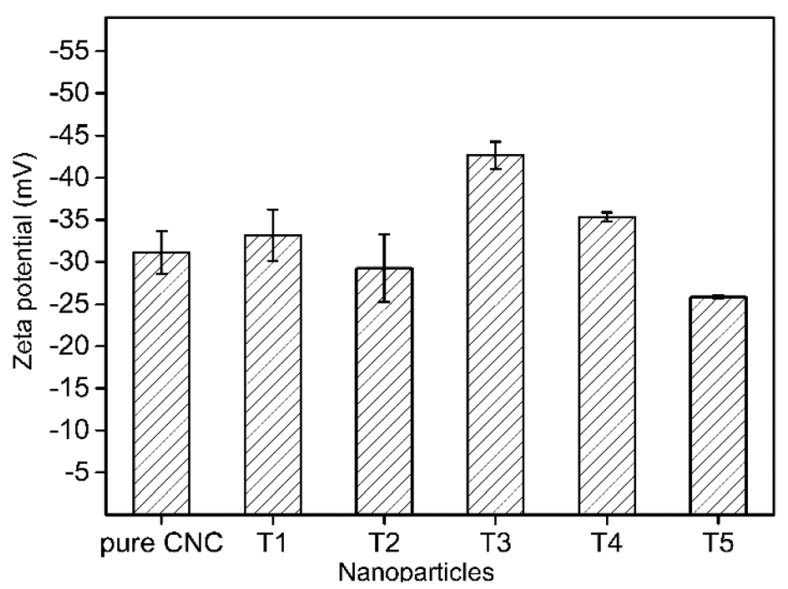

Fig. 5 Zeta potential of AgNPs stabilized by CNC. 

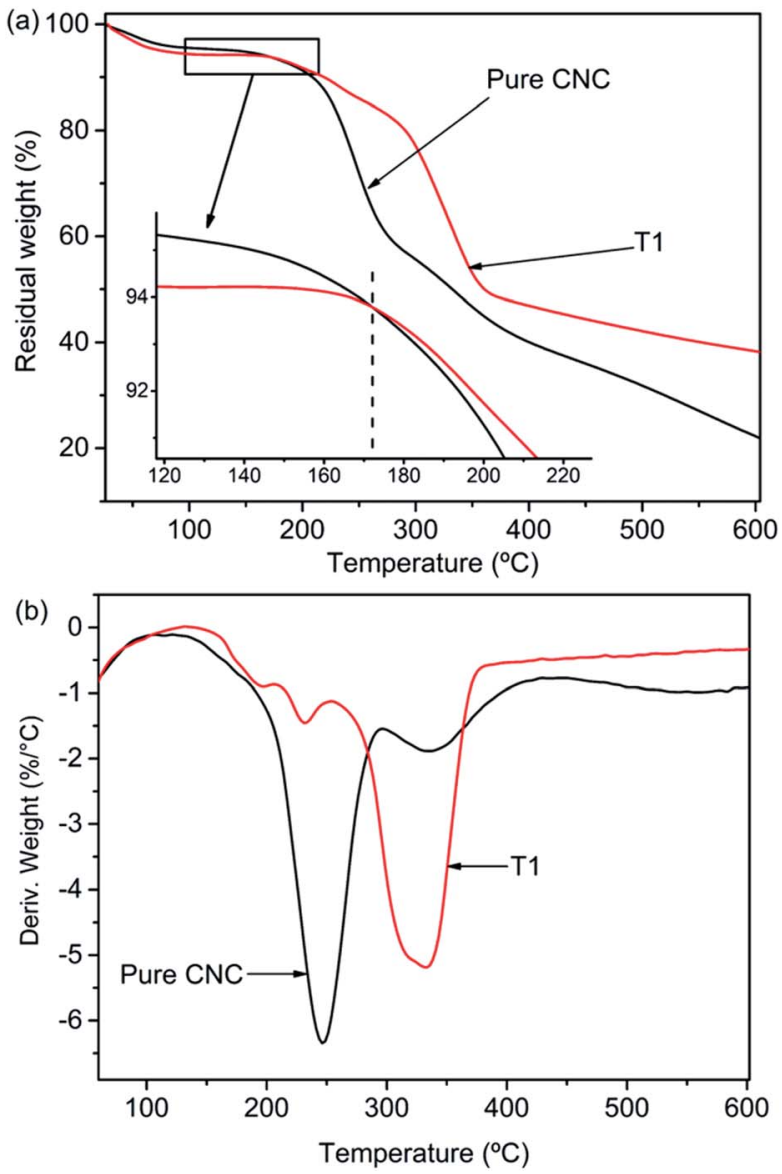

Fig. 6 (a) TGA and (b) DTG thermograms of AgNPsaCNC.

the char residue. The temperature associated with $50 \%$ mass reduction of neat CNC and AgNPs@CNC were $\sim 331{ }^{\circ} \mathrm{C}$ and $\sim 358{ }^{\circ} \mathrm{C}$ respectively, and the maximum thermal decomposition temperatures $\left(T_{\max }\right.$ shown in Fig. $\left.5 \mathrm{~b}\right)$ of pure CNC and AgNPs@CNC were $\sim 246{ }^{\circ} \mathrm{C}$ and $\sim 333{ }^{\circ} \mathrm{C}$, respectively. This could be ascribed to the existence of the AgNPs on the CNC surface, which reinforced the thermal stability of the CNC. The AgNPs reduced the migration of the CNC chains which inhibited the transfer of free radicals, thereby limiting the interchain reaction so that the degradation of the CNC occurred at higher temperatures. ${ }^{68}$ It was also possible that small and dense AgNPs interacted with the CNC surface to delay further decomposition of the material.

\subsection{Antimicrobial activity}

In the antibacterial activity test, the different concentrations of pure CNC suspension (i.e., $0.5 \mathrm{mg} \mathrm{mL}^{-1}$ and $1.5 \mathrm{mg} \mathrm{mL}^{-1}$ ) and deionized water were selected as controls. No antibacterial activity was observed for pure CNC suspension and deionized water (Fig. S3†). However, the incorporation of the AgNPs into the CNC surface caused antibacterial activity, and the CNC suspension exhibited significant inhibition against bacterial growth (Fig. 7). Because pure CNC suspension and deionized water did not have any antibacterial activity, the antibacterial activity of the
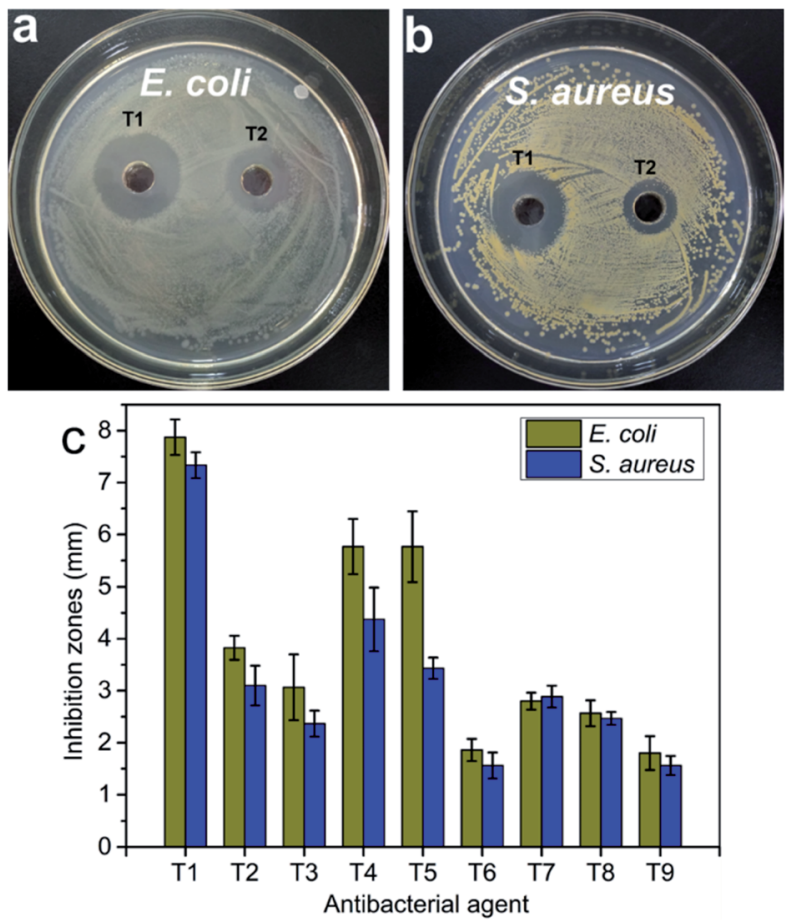

Fig. 7 The photos of the antibacterial activity of AgNPs@CNC samples $(a, b)$ and $(c)$ the inhibition zones measured by using the vernier caliper.

AgNPs@CNC suspension was directly influenced to the presence of the formed AgNPs. The concentration of $\mathrm{Ag}^{+}$plays a crucial role in the antibacterial activity. In Fig. 7c, T1-T3, T4-T6 and T7-T9 samples revealed that as the amount of silver nitrate added gradually decreases, the inhibition zone of $E$. coli and $S$. aureus decreases, respectively. Similarly, using extreme range analysis indicated that the concentrations of $\mathrm{CNC}$, and the power of the microwave and the time of reaction have less influence on the antibacterial activity than concentrations of $\mathrm{Ag}^{+}$. With minimal use of silver nitrate, the T1 sample in the orthogonal assay showed excellent antibacterial activity against both $E$. coli and $S$. aureus in Fig. $7 \mathrm{a}$ and $\mathrm{b}$. In addition, the width of the inhibition zone of the orthogonal assay samples basically corresponds to the intensity of the UV absorption peak at $420 \mathrm{~nm}$. The respective width of inhibition zones for the T1 samples were found as $7.87 \pm$ $0.34 \mathrm{~mm}$ and $7.33 \pm 0.25 \mathrm{~mm}$ for E. coli and S. aureus (Fig. 7c), respectively. In this MIC assay, $1.5 \mathrm{mg} \mathrm{mL}^{-1} \mathrm{CNC}$ and deionized water were selected as controls. The MIC of T1 sample for $E$. coli and $S$. aureus were both $10.6 \mu \mathrm{g} \mathrm{mL} \mathrm{m}^{-1}$, these values compare favourably with other experiments conducted with the commercial AgNPs. ${ }^{9}$ In the orthogonal assay design, although the T1 used the most $\mathrm{AgNO}_{3}$ to synthesize AgNPs, the amount of $\mathrm{AgNO}_{3}$ required by the $\mathrm{T} 1$ sample was only $0.03 \mathrm{mM}(\sim 0.01 \mathrm{wt} \%)$. These antibacterial test results indicated that high levels of antibacterial activity could still be achieved with trace amounts of $\mathrm{AgNO}_{3}$.

\section{Conclusions}

In this study, we successfully synthesized AgNPs with CNC as the carrier via microwave reaction reduction. The UV/vis absorbance spectra showed a large amount of $\mathrm{Ag}$ in the 
suspension of AgNPs@CNC, especially sample T1, because the absorption peak at $420 \mathrm{~nm}$ is very high. The surface morphology and analysis of XRD indicated that there were a large number of small AgNPs on the CNC surface of the T1 sample. Structural characterization indicated that chemical bonds were not formed between AgNPs and CNC. This may be because the AgNPs were merely physically adsorbed on the CNC surface, as $\mathrm{CNC}$ has a large surface to volume ratio and negatively charged surface. The zeta potential analysis revealed T1 sample could be as stable as pure CNC suspension. In addition, TGA illustrated that the thermal stability of AgNPs@CNC was better than that of pure CNC, and this further illustrates that a large number of AgNPs were adsorbed on the CNC surface, which prevents the rapid decomposition of $\mathrm{CNC}$ at high temperatures. The antibacterial activity of $\mathrm{T} 1$ sample exhibited that only using $0.03 \mathrm{mM}(\sim 0.01 \mathrm{wt} \%) \mathrm{AgNO}_{3}$ to synthesize AgNPs@CNC could achieve good antibacterial activity. Therefore, this green, facile, and effective method reported in the present study may be promising way for the synthesis of AgNPs.

\section{Conflicts of interest}

There are no conflicts to declare.

\section{Acknowledgements}

This research was funded by Science and Technology Innovation Project for Social Undertaking and Livelihood System of Chongqing (Grant No. cstc2017shmsA30018), the Science and Technology Project of Chongqing City Administration Bureau (Grant No. 2019-26).

\section{References}

1 R. J. Moon, A. Martini, J. Nairn, J. Simonsen and J. Youngblood, Chem. Soc. Rev., 2011, 40, 3941-3994.

2 N. Lin, J. Huang and A. Dufresne, Nanoscale, 2012, 4, 32743294.

3 K. B. Male, A. C. W. Leung, J. Montes, A. Kamen and J. H. T. Luong, Nanoscale, 2012, 4, 1373-1379.

4 Y. Habibi, L. A. Lucia and O. J. Rojas, Chem. Rev., 2010, 110, 3479-3500.

5 E. Csiszar, P. Kalic, A. Kobol and E. d. P. Ferreira, Ultrason. Sonochem., 2016, 31, 473-480.

6 S. Eyley and W. Thielemans, Nanoscale, 2014, 6, 7764-7779.

7 Z. Hosseinidoust, M. N. Alam, G. Sim, N. Tufenkji and

T. G. M. van de Ven, Nanoscale, 2015, 7, 16647-16657.

8 K. J. De France, M. Badv, J. Dorogin, E. Siebers, V. Panchal, M. Babi, J. Moran-Mirabal, M. Lawlor, E. D. Cranston and T. Hoare, ACS Biomater. Sci. Eng., 2019, 5, 2235-2246.

9 S. Wang, J. Sun, Y. Jia, L. Yang, N. Wang, Y. Xianyu, W. Chen, X. Li, R. Cha and X. Jiang, Biomacromolecules, 2016, 17, 24722478.

10 H. Rosilo, J. R. McKee, E. Kontturi, T. Koho, V. P. Hytonen, O. Ikkala and M. A. Kostiainen, Nanoscale, 2014, 6, 1187111881.
11 S. Eyley, D. Vandamme, S. Lama, G. Van den Mooter, K. Muylaert and W. Thielemans, Nanoscale, 2015, 7, 1441314421.

12 Y. Li, S. Wang, R. Huang, Z. Huang, B. Hu, W. Zheng, G. Yang and X. Jiang, Biomacromolecules, 2015, 16, 780-789.

13 N. Yanamala, M. T. Farcas, M. K. Hatfield, E. R. Kisin, V. E. Kagan, C. L. Geraci and A. A. Shvedova, ACS Sustainable Chem. Eng., 2014, 2, 1691-1698.

14 R. M. Domingues, M. E. Gomes and R. L. Reis, Biomacromolecules, 2014, 15, 2327-2346.

15 J. Yang, C. R. Han, F. Xu and R. C. Sun, Nanoscale, 2014, 6, 5934-5943.

16 D. Gebauer, V. Oliynyk, M. Salajkova, J. Sort, Q. Zhou, L. Bergström and G. Salazar-Alvarez, Nanoscale, 2011, 3, 3563-3566.

17 W. H. Eisa, A. M. Abdelgawad and O. J. Rojas, ACS Sustainable Chem. Eng., 2018, 6, 3974-3983.

18 M. S. Wang, F. Jiang, Y.-L. Hsieh and N. Nitin, J. Mater. Chem. $B, 2014,2,6226-6235$.

19 K. K. Sadasivuni, A. Kafy, L. D. Zhai, H. U. Ko, S. Mun and J. Kim, Small, 2015, 11, 994-1002.

20 Z. Zhang, Q. Wu, K. Song, S. Ren, T. Lei and Q. Zhang, ACS Sustainable Chem. Eng., 2015, 3, 574-582.

21 Y.-D. Li, H. Li, A.-K. Du, M. Wang and J.-B. Zeng, Polym. Test., 2017, 59, 1-9.

22 T.-D. Nguyen, W. Y. Hamad and M. J. MacLachlan, Adv. Funct. Mater., 2014, 24, 777-783.

23 A. G. Dumanli, H. M. van der Kooij, G. Kamita, E. Reisner, J. J. Baumberg, U. Steiner and S. Vignolini, ACS Appl. Mater. Interfaces, 2014, 6, 12302-12306.

24 M. Giese, L. K. Blusch, M. K. Khan and M. J. MacLachlan, Angew. Chem., Int. Ed. Engl., 2015, 54, 2888-2910.

25 H. Therien-Aubin, A. Lukach, N. Pitch and E. Kumacheva, Nanoscale, 2015, 7, 6612-6618.

26 T. C. Mokhena and A. S. Luyt, Carbohydr. Polym., 2017, 165, 304-312.

27 S. Jain, G. Bhanjana, S. Heydarifard, N. Dilbaghi, M. M. Nazhad, V. Kumar, K. H. Kim and S. Kumar, Carbohydr. Polym., 2018, 202, 219-226.

28 Z. Shi, J. Tang, L. Chen, C. Yan, S. Tanvir, W. A. Anderson, R. M. Berry and K. C. Tam, J. Mater. Chem. B, 2015, 3, 603611.

29 M. S. Islam, N. Akter, M. M. Rahman, C. Shi, M. T. Islam, H. Zeng and M. S. Azam, ACS Sustainable Chem. Eng., 2018, 6, 9178-9188.

30 L. C. Shan Lin, L. Huang, S. Cao, X. Luo and K. Liu, Ind. Crops Prod., 2015, 70, 395-403.

31 A. Celebioglu, F. Topuz, Z. I. Yildiz and T. Uyar, Carbohydr. Polym., 2019, 207, 471-479.

32 H. Li, Q. Chen, J. Zhao and K. Urmila, Sci. Rep., 2015, 5, 11033.

33 D. D. Bannerman, M. J. Paape, J. W. Lee, X. Zhao, J. C. Hope and P. Rainard, Clin. Diagn. Lab. Immunol., 2004, 11, 463472.

34 N. Chanter, G. A. Hall, A. P. Bland, A. J. Hayle and K. R. Parsons, Vet. Microbiol., 1986, 12, 241-253.

35 M. M. Levine, J. Infect. Dis., 1987, 155, 377-389. 
36 L. Zhu, D. Guo, L. Sun, Z. Huang, X. Zhang, W. Ma, J. Wu, L. Xiao, Y. Zhao and N. Gu, Nanoscale, 2017, 9, 5489-5498.

37 M. M. G. Fouda, N. R. Abdelsalam, I. M. A. Gohar, A. E. M. Hanfy, S. I. Othman, A. F. Zaitoun, A. A. Allam, O. M. Morsy and M. El-Naggar, Colloids Surf., B, 2020, 188, 110805.

38 Z. Yu, W. Wang, R. Dhital, F. Kong, M. Lin and A. Mustapha, Colloids Surf., B, 2019, 180, 212-220.

39 N. Drogat, R. Granet, V. Sol, A. Memmi, N. Saad, C. Klein Koerkamp, P. Bressollier and P. Krausz, J. Nanopart. Res., 2010, 13, 1557-1562.

40 U. Klueh, V. Wagner, S. Kelly, A. Johnson and J. Bryers, J. Biomed. Mater. Res., 2000, 53, 621-631.

41 C. Kumar, S. Howdle and H. Münstedt, J. Biomed. Mater. Res., Part B, 2005, 75, 311-319.

42 Q. Xu, W. Zheng, P. Duan, J. Chen, Y. Zhang, F. Fu, H. Diao and X. Liu, Carbohydr. Polym., 2019, 204, 42-49.

43 N. M. Zain, A. G. Stapley and G. Shama, Carbohydr. Polym., 2014, 112, 195-202.

44 J. Wongpreecha, D. Polpanich, T. Suteewong, C. Kaewsaneha and P. Tangboriboonrat, Carbohydr. Polym., 2018, 199, 641648.

45 A. Goel, M. K. Meher, P. Gupta, K. Gulati, V. Pruthi and K. M. Poluri, Carbohydr. Polym., 2019, 206, 854-862.

46 R. Zhao, W. Kong, M. Sun, Y. Yang, W. Liu, M. Lv, S. Song, L. Wang, H. Song and R. Hao, ACS Appl. Mater. Interfaces, 2018, 10, 17617-17629.

47 X. Chen, X. Huang, C. Zheng, Y. Liu, T. Xu and J. Liu, J. Mater. Chem. B, 2015, 3, 7020-7029.

48 J. George, V. A. Sajeevkumar, K. V. Ramana, S. N. Sabapathy and Siddaramaiah, J. Mater. Chem., 2012, 22, 22433-22439.

49 A. R. Lokanathan, K. M. Uddin, O. J. Rojas and J. Laine, Biomacromolecules, 2014, 15, 373-379.

50 H. Liu, D. Wang, Z. Song and S. Shang, Cellulose, 2010, 18, 67-74.

51 W. Lu, J. Sun and X. Jiang, J. Mater. Chem. B, 2014, 2, 23692380.

52 S.-M. Li, N. Jia, M.-G. Ma, Z. Zhang, Q.-H. Liu and R.-C. Sun, Carbohydr. Polym., 2011, 86, 441-447.
53 S.-M. Li, N. Jia, J.-F. Zhu, M.-G. Ma, F. Xu, B. Wang and R.-C. Sun, Carbohydr. Polym., 2011, 83, 422-429.

54 L.-H. Fu, Q.-L. Gao, C. Qi, M.-G. Ma and J.-F. Li, Nanomaterials, 2018, 8, 978.

55 Y.-Y. Dong, S. Liu, Y.-J. Liu, L.-Y. Meng and M.-G. Ma, J. Mater. Sci., 2017, 52, 8219-8230.

56 T. Tang, J. Zhu, W. Wang and H. Ni, Polym. Eng. Sci., 2018, 59, 928-934.

57 S. Perera, B. Bhushan, R. Bandara, G. Rajapakse, S. Rajapakse and C. Bandara, Colloids Surf., A, 2013, 436, 975-989.

58 A. Ahmad, P. Mukherjee, S. Senapati, D. Mandal, M. I. Khan, R. Kumar and M. Sastry, Colloids Surf., B, 2003, 28, 313-318.

59 Y.-K. Twu, Y.-W. Chen and C.-M. Shih, Powder Technol., 2008, 185, 251-257.

60 A. D. French, Cellulose, 2013, 21, 885-896.

61 Y. Nishiyama, J. Sugiyama, H. Chanzy and P. Langan, J. Am. Chem. Soc., 2003, 125, 14300-14306.

62 Z. X. Wang, X. B. Chen, M. Chen and L. M. Wu, Langmuir, 2009, 25, 7646-7651.

63 Z. Li, L. Wang, S. Chen, C. Feng, S. Chen, N. Yin, J. Yang, H. Wang and Y. Xu, Cellulose, 2014, 22, 373-383.

64 T. C. Kaspar, T. Droubay, S. A. Chambers and P. S. Bagus, J. Phys. Chem. C, 2010, 114, 21562-21571.

65 D. W. Boukhvalov, I. S. Zhidkov, E. Z. Kurmaev, E. Fazio, S. O. Cholakh and L. D'Urso, Carbon, 2018, 128, 296-301.

66 K. Kawai, T. Narushima, K. Kaneko, H. Kawakami, M. Matsumoto, A. Hyono, H. Nishihara and T. Yonezawa, Appl. Surf. Sci., 2012, 262, 76-80.

67 B. J. Murray, O. Li, J. T. Newberg, E. J. Menke, J. C. Hemminger and R. M. Penner, Nano Lett., 2005, 5, 2319-2324.

68 Z. H. Mbhele, M. G. Salemane, C. G. C. E. van Sittert, J. M. Nedeljkovic, V. Djokovic and A. S. Luyt, Chem. Mater., 2003, 15, 5019-5024.

69 D. S. Singare, S. Marella, K. Gowthamrajan, G. T. Kulkarni, R. Vooturi and P. S. Rao, Int. J. Pharm., 2010, 402, 213-220. 